\title{
A INFLUÊNCIA DAS RELAÇÕES INTERDISCIPLINARES E DA TEORIA DO PRAGMATISMO NA APLICAÇÃO DAS CLÁUSULAS EXORBITANTES NA CONTRATAÇÃO GOVERNAMENTAL
}

Gilmar Brunizio $^{180}$

Recebido em: 20/06/2016

Aprovado em: 22/07/2016

\begin{abstract}
RESUMO
O presente artigo por abordagem qualitativa, desenvolveu pesquisa bibliográfica sobre os divergentes entendimentos doutrinários acerca das cláusulas exorbitantes conferidas à Administração Pública. Os conflitos na relação jurídica das contratações governamentais não deverão ser resolvidos por intermédio de interpretação absolutista da supremacia de um interesse sobre o outro ou por exclusiva ponderação de valores dos direitos conflitantes. A proposta de um novo paradigma busca incrementar a interpretação no momento do ato, estabelecendo concepções relativas aos aspectos da relação interdisciplinar, empírico e pragmático. $\mathrm{O}$ método proposto se trata da analise final do momento da decisão que observará se a decisão afetará outros sistemas e, ainda, as consequências prováveis e imediatas, com o desiderato de resguardar o bem comum, sem descartar a normatividade. Portanto, ao julgador impõe-se o dever de observar os prováveis resultados, com o fim de resguardar a finalidade fundamental do Estado, ainda que a decisão seja proporcional ou não venha privilegiar o interesse de governo.
\end{abstract}

Palavras-chave: Clausulas. Exorbitantes. Pragmatismo.

\section{INTRODUÇÃO}

Não temos dúvidas que a Administração Pública paga caro pelos seus privilégios de supremacia sobre o particular, pois toda imposição exacerbada de obrigações ou riscos assumidos pelo particular são transferidos para os custos da contratação. É o momento de acalmar os ânimos, fugir dos debates teóricos e criar alternativas para harmonizar os interesses e garantir segurança na contratação governamental.

\footnotetext{
${ }^{180}$ Mestrando em Direito pela Universidade Veiga de Almeida. Especialista em Direito do Estado e Administrativo pela Universidade Gama Filho, UGF. Advogado.
} 
Existem correntes doutrinárias divergentes sobre o tema. Juristas tradicionais firmam entendimento no sentido da prevalência do interesse da coletividade sobre do particular. Enquanto que os juristas modernos propõem sua desconstrução, sendo o princípio da proporcionalidade o ponto central de ponderação dos valores e harmonização dos conflitos. Fato é que ao final, ambas as correntes são convergentes em seus objetivos de assegurar o bem comum, do mesmo modo, nenhum deles prescinde de garantir os direitos dos particulares, seja no sentido de reequilibrar a relação contratual ou até mesmo indenizá-los por possíveis perdas e danos.

Em decorrência da normatividade vigente persiste a prevalência do interesse público sobre o privado nas contratações governamentais, posto que a Administração Pública detém prerrogativas para assegurar a obtenção do bem almejado, dentre estas a inserção de cláusulas exorbitantes aos contratos privados nos contratos administrativos ${ }^{181}$. Não obstante, o crescimento de julgadores que adotam a teoria moderna, ao decidir os conflitos de interesses, por intermédio da ponderação dos valores, no qual prevalecerão aqueles que melhor venham atender os direitos fundamentais ou garantir o bem comum.

O presente ensaio introduz um novo paradigma no exercício das cláusulas exorbitantes, sem pugnar pela desconstrução da doutrina tradicional e não utilização da teoria moderna, se propõe observar, no momento da decisão, aspectos interdisciplinares, empíricos e pragmáticos nos atos administrativos e decisões que envolvam o exercício das prerrogativas da Administração perante o particular nos contratos administrativos.

Para isso no primeiro capítulo se desenvolve a comparação dos entendimentos tradicionalistas em face dos entendimentos contemporâneos. Se por um lado, a doutrina tradicional defende a existência da supremacia do interesse público sobre o interesse privado, como Celso Antônio Bandeira de Melo, Maria Silvia Di Pietro e outros ${ }^{182}$. Do outro, doutrinadores modernos, defendem que a aplicabilidade da supremacia deve ser moderada com a finalidade de garantir direitos fundamentais e preservar a liberdade econômica, nessa esteira, estão Daniel Sarmento, Alexandre Aragão, Humberto Ávila, dentre outros.

\footnotetext{
${ }^{181}$ Atualmente tramita no Senado Federal o Projeto de Lei n $^{\mathbf{3}} 349,2015$ que propõe Incluir na Lei de Introdução às Normas do Direito Brasileiro (Decreto-lei n. 4.657, de 1942), disposições sobre segurança jurídica e eficiência na criação e aplicação do direito público. Em seu conteúdo fica límpido a adoção da teoria do pragmatismo ao estabelecer que vedado ao agente público decidir sem medir as consequências, bem como, leva em consideração o momento do ato e as circunstâncias que o fizeram fazer aquela escolha.

${ }^{182}$ Importante advertir que há juristas modernos que defendem a preponderância do princípio da supremacia do interesse público sobre o privado, tanto quanto a doutrina tradicional, como por exemplo: Emerson Gabardo e Daniel Wunder Hachem.
} 
No segundo capítulo apresenta-se o conceito das cláusulas exorbitantes e sua aplicação no cotidiano, refazendo-se uma leitura de seus objetivos diante do Estado do bem-social e da constituição econômica, em que a iniciativa privada deve sofrer intervenção estatal apenas para garantir direitos fundamentais e distribuir cidadania social.

Por fim, no último capítulo, apresentamos um novo paradigma do Direito Administrativo, propondo uma nova metodologia filosófica e jurídica para dirimir os conflitos de interesses nas contratações governamentais no que tange a aplicação das cláusulas exorbitantes, num estilo de interpretação finalística, empírica, interdisciplinar e pragmática.

Esse capítulo traz dois exemplos. O primeiro, o caso da tarifa zero no transporte de passageiros do Município de Maricá, demonstrando que a decisão não levou em consideração a relação interdisciplinar e não foi pragmática, na medida que a qualquer custo concedeu o interesse público primário de ir e vir, sem observar as consequências negativas imediatas e futuras ao erário municipal. O segundo exemplo, que aborda a rescisão unilateral de um contrato administrativo, ficou claro a aplicação de cláusulas exorbitantes também consubstancia uma decisão pragmática, na medida que poderá cessar prejuízos ao interesse da coletividade.

Para o método proposto não é relevante se há supremacia de uma parte sobre a outra, muito menos indica desrespeito ao ordenamento jurídico, apenas sugere que a Administração ou o magistrado ao praticar o ato discricionário ou decisório leve em consideração as suas consequências e busquem a finalidade fundamental de alcançar o bem comum e os objetivos constitucionais.

\section{AS DIVERGÊNCIAS E CONVERGÊNCIAS DA DOUTRINA BRASILEIRA SOBRE O PRINCÍPIO DA SUPREMACIA DO INTERESSE PÚBLICO SOBRE O PRIVADO}

Embora as correntes dos publicitas nacionais tradicionais e modernos sejam divergentes, na medida que a primeira corrente defende sua existência, ao passo de considerá-la como axioma $^{183}$ a última defende até sua desconstrução. Entretanto, ambas admitem a importância dos argumentos de cada lado.

Bandeira de Melo (2014, p. 72), assim afirma: "Por isso, o uso das prerrogativas da Administração é legítimo se, quando e na medida indispensável ao atendimento dos interesses públicos”. A compreensão do publicista se assemelha a dos juristas modernos, indicando que a

${ }^{183}$ Sobre esse entendimento ver Bandeira de Melo (2014, p. 70) 
aplicação da supremacia do interesse público sobre o privado deve ocorrer quando for indispensável ao interesse público, quer dizer, não descarta a ponderação de valores para decidir sobre a prevalência dos interesses.

Com a mesma cautela, Daniel Sarmento (2005, p. 28) converge: "a desvalorização total dos interesses públicos diante dos particulares pode conduzir à anarquia e ao caos geral, inviabilizando qualquer possibilidade de regulação coativa da vida humana em comum". Assim sendo, o jurista pressupõe que a supremacia do interesse público sobre o privado serve como um freio para o Estado não se tornar liberal, em sentido amplo.

Portanto, de forma ideológica não há polaridade de pensamentos entre os juristas tradicionais e modernos, posto que ao final ambos possuem o objetivo de garantir o bem comum $^{184}$.

À vista disso, o entendimento que há convergência ideológica entre os doutrinadores pátrios é indefectível, como corrobora o jurista Humberto Ávila (2007, P. 13):

O interesse privado e o interesse público estão de tal forma instituídos pela Constituição brasileira que não podem ser separadamente descritos na análise da atividade estatal e de seus fins. (p. ex. preambulo e direitos fundamentais). Por isso afirma HÄBERLE, referindo-se à Lei fundamental Alemã, muito menos insistente na proteção da esfera privada do que a brasileira: "Exagerando: o interesse privado é um ponto de vista que faz do conteúdo do bem comum da Constituição". Em vez de uma relação de contradição entre os interesses privado e público, há em verdade, uma conexão estrutural (ein struktureller Zusammenhang).

Afastando-se da seara ideológica, ainda que o princípio da supremacia do interesse público sobre o privado possa garantir o bem comum, importa, em igual sentido, que garantir os direitos dos particulares poderá proporcionar segurança jurídica que, por via de consequência, encoraja os indivíduos a desenvolver suas atividades econômicas e contratar com a Administração Pública. Logo, atender os interesses privados em muitos casos significa atender, sobremaneira, o interesse público.

Além dos divergentes pensamentos sobre a forma de solução dos conflitos entre interesses públicos e privados, merece destaque a divisão clássica do interesse público, em primário e secundário. Sendo o primeiro as finalidades fundamentais do Estado e o segundo atos de governabilidade. Luís Roberto Barroso, destaca que o interesse público primário não é objeto de ponderação, logo, admite a prevalência do interesse público nestas hipóteses. Este jurista sob o manto da teoria liberal de John Rawls, acrescenta que no caso de conflito entre

\footnotetext{
${ }^{184}$ Moreira Neto (2014, p. 10), conceitua o que é bem comum: “O interesse público, legalmente definido como o que está a posto sob a responsabilidade do Estado e tido como finalidade de sua ação, não é outro senão, em síntese o interesse geral da sociedade, ou em se preferindo, o bem comum.
} 
interesses primários a interpretação deve ser realizada sob os auspícios da dignidade da pessoa humana e da razão pública. (BARROSO, 2005, apud SARMENTO, 2005, p. XVI)

Essa divisão, ao nosso ver, é apenas pedagógica, pois ainda que o interesse público secundário possa ser relativizado, por muitas vezes, é através dele que se pode alcançar o interesse público primário, por tais motivos entendemos que deve ser preservado da mesma forma. Defendemos que a proteção do erário é fundamental para garantir direitos sociais aos hipossuficientes que ultima o equilíbrio do status social ${ }^{185}$, assim sendo, protegê-lo ou dar-lhe prioridade aos interesses alheios estar-se-á de forma indireta garantindo interesses públicos primários, isto é, alcançando a finalidade pública fundamental do Estado, razão pela qual no caso concreto o interesse público secundário poderá merecer prevalência sobre os demais.

Não há dúvidas que a modificação do Estado, após o fenômeno do pós-positivismo e liberalização de atividades econômicas ocorrida nos anos $80^{186}$, transformou o princípio da supremacia do interesse público sobre o privado, todavia, nosso sistema jurídico ainda contém normas que estabelecem esta superioridade, como as cláusulas exorbitantes nos contratos administrativos, cujo passaremos a estudá-las.

\section{CONCEITO DAS CLÁUSULAS EXORBITANTES}

O contrato administrativo é um ajuste de vontades, como os contratos comuns. Nessa espécie a Administração Pública faz parte da avença e o objeto contratado visa alcançar alguma finalidade pública. O presente ensaio é restrito a aplicação das cláusulas exorbitantes na espécie chamada contrato administrativo propriamente dito ${ }^{187}$, embora existam outras espécies de relação contratual em que a Administração Pública é parte.

O que diferencia o contrato administrativo propriamente dito das demais espécies de contratos é a supremacia de poder da Administração Pública que estabelece de forma unilateral os termos contratuais, inclusive, tendo a prerrogativa de criar cláusulas exorbitantes aos contratos comuns. Tais cláusulas se estabelecidas no direito privado seriam nulas, na medida que criam desigualdade entre as partes.

Cretella Junior (1985, p. 8) assim define as prerrogativas contidas no contrato administrativo a favor da Administração Pública: “Desse modo, 'cláusula exorbitante’ é a

\footnotetext{
185 Sobre esse tema ver Marshall (1967, p. 95)

${ }^{186}$ Aragão (2013, p. 243), descreve de forma precisa as transformações dos serviços públicos no Brasil.

${ }^{187}$ Sobre definição das espécies de contrato administrativo consultar Marçal (2014, P. 918)
} 
proposição mandamental, formulada pela administração e aceita pelo particular, e que, inscrita entre as demais cláusulas do contrato, tipifica-o como administrativo". ${ }^{188}$

Sempre, portanto, que a Administração impor sua supremacia de poder público para contratar particular, gozará de prerrogativas para garantir a finalidade pública, no qual a Administração Pública por meio de atos unilaterais poderá alterar os direitos e deveres do contratado, exclusive as cláusulas econômicas do contrato.

Esses privilégios estão dispostos no art. 58 da Lei no 8.666/93 que apresenta rol de prerrogativas que facultam sua aplicação nos contratos administrativos, quais sejam: a) modificá-los, unilateralmente, para melhor adequação às finalidades de interesse público, respeitados os direitos do contratado; b) rescindi-los, unilateralmente, nos casos especificados no inciso I do art. 79 desta Lei; c) fiscalizar lhes a execução; d) aplicar sanções motivadas pela inexecução parcial ou total do ajuste; e) nos casos de serviços essenciais, ocupar provisoriamente bens móveis, imóveis, pessoal e serviços vinculados ao objeto do contrato, na hipótese da necessidade de acautelar apuração administrativa de faltas contratuais pelo contratado, bem como na hipótese de rescisão do contrato administrativo.

Numa primeira análise, constata-se que as cláusulas exorbitantes consubstanciam a supremacia do interesse público sobre o privado. O que é de fato. Contudo, o sistema jurídico que regula as contratações públicas possui diversos comandos que afiançam a manutenção dos direitos do administrado, seja para equilibrar a relação contratual ou para indenizá-1o ${ }^{189}$.

\section{O NOVO PARADIGMA DO DIREITO ADMINISTRATIVO ADEQUADO AS CLÁUSULAS EXORBITANTES}

Nos capítulos anteriores, de forma breve, traçamos os entendimentos dos juristas tradicionais e modernos acerca do princípio da supremacia do interesse público sobre o privado

\footnotetext{
188 O Autor prefere denominá-las de cláusulas de privilégio, uma vez que chamá-las de cláusulas exorbitantes, significa dizer que tais clausulas estão fora da orbita do direito civil, portanto, parece que o contrato público se baseia em seu nascedouro do direito civil, apenas diferenciando-se pela inclusão de normas que desiquilibram a relação contratual. (CRETELLA JUNIOR, 1985, p.9)

189 Assim tem decidido o STJ: “ADMINISTRATIVO. CONTRATO ADMINISTRATIVO. RESCISÃO UNILATERAL. INDENIZAÇÃO POR LUCROS CESSANTES. CABIMENTO. 1. A rescisão do contrato administrativo por ato unilateral da Administração Pública, sob justificativa de interesse público, impõe ao contratante a obrigação de indenizar o contratado pelos prejuízos daí decorrentes (art. 69, I, § $2^{\circ}$, do Decreto-Lei 2.300/86; art. 79, $\S 2^{\circ}$ da Lei 8.666/93), como tais considerados, não apenas os danos emergentes, mas também os lucros cessantes (CC/1916, art. 1.059; CC/2002, art. 402). Precedentes. 2. Embargos de divergência a que se dá provimento. (EREsp 737741 / RJ - EMBARGOS DE DIVERGENCIA EM RECURSO ESPECIAL 2008/0110646-7 - Min. TEORI ALBINO ZAVASCKI).
} 
e das cláusulas exorbitantes contidas nos contratos administrativos. Chegamos à conclusão que há convergência ideológica dos pensadores e que a supremacia do interesse público possui o objetivo de assegurar o interesse geral sem afetar os direitos dos particulares.

A título de demonstração, o publicista Meireles (2015, p. 241) defende que: "Daí por que já decidimos que nos contratos celebrados pela coletividade não se pode interpretar suas cláusulas contra essa mesma coletividade, para só se atender aos direitos individuais do particular contratado".

Com o novo paradigma proposto a interpretação das cláusulas dar-se-á visando atender ao interesse da coletividade, mas não sob o ponto de vista ora colocado por Hely Lopes Meireles, em verdade o interesse da coletividade será visto através de uma análise interdisciplinar, empírica e pragmática.

Incialmente é importante salientar que o interesse público não é imutável, ele deve ser analisado no momento da decisão, nas circunstâncias em que se dará o ato e de acordo com os seus resultados, haja vista que determinado interesse coletivo poderá ser modificado até mesmo que seja para atender o interesse do particular, pois num caso concreto, como já vimos, atender o interesse privado pode ser tão relevante quanto atender o interesse público.

O novo paradigma foi proposto e abordado, de forma acertada e contemporânea, pelo publicista Mendonça (2014a, 179), ao indicá-lo como parâmetro de aplicação no Direito Administrativo:

\begin{abstract}
O ensaio defende que a verdadeira mudança de paradigmas do direito administrativo não ocorreu com a ascensão, teórica e prática, de ideias como a relativização da noção de supremacia do interesse público, mas com uma mudança na abordagem metodológica e conceitual da disciplina. O novo estilo de direito administrativo é pragmatista, empiricista, assistematizador e assistemático, e cético em relação à centralidade do discurso jurídico.
\end{abstract}

Fica evidente o novo paradigma, quando Mendonça (2014a, p. 306) leciona sobre poder de polícia:

\begin{abstract}
O exercício do poder de polícia não pode implicar a prática de atos administrativos que tratem o homem como meio para um fim; que lhe imprimam insuportável sofrimento físico e/ou mental. É claro que o critério vai se prestar a alguma utilização retórica, tanto que na maioria dos casos, impor restrições a direitos não é circunstância que o particular aceite com sorrisos. Mas a violação à dignidade humana, no ato de polícia, é muito mais do que o desconforto com a atuação da Administração Ordenadora. (...)
\end{abstract}

Nosso trabalho foi apenas de adequá-lo, de forma especifica, as cláusulas exorbitantes contidas na relação contratual entre a Administração e o particular, no qual o intérprete deverá 
observar se o exercício da clausula de privilegio atenderá, de forma ampla, a finalidade pública, se preservará a livre iniciativa privada e garantirá direitos fundamentais.

Destarte, não há margem para decisões tradicionais eivadas de interpretações autoritárias de supremacia de uma parte sobre a outra ou incansáveis ponderações de valores. Atualmente, numa relação contratual administrativa impõe-se observar aspectos empíricos, interdisciplinares 190 e pragmáticos.

Tais alterações na interpretação proposta neste ensaio, se baseia na conjugação de teorias jurídicas, filosóficas, sociológicas e econômicas, levando em consideração o advento do período denominado pós-positivismo, no qual as normas deixam de ser o centro das atenções e direitos naturais passam a integrar as relações, sobretudo, na relação entre o Estado e indivíduo.

Neste contexto que entendemos que não há margem, nos dias de hoje, de aplicação de um sistema jurídico que seja operativamente fechado, quer dizer, no direito as diferenças entre fatos e normas se resolve sob o comando da normatividade, de acordo com o entendimento de Niklas Luhmann. (CAMPILONGO, 2005, p. 44). É irrefutável que não se deve tratar tais diferenças sob o manto isolado da normatividade, sem observar os aspectos políticos e econômicos, como instrui Eros Grau:

Isso significa que a norma é produzida pelo intérprete, não apenas a partir de elementos que se despreendem do texto [mundo do dever-ser], mas também a partir de elementos do caso [= dos fatos] ao qual será ela aplicada, isto é, a partir de elementos da realidade [mundo do ser]).

Nossa proposta induz o agente público ou magistrado afugentar-se da ideologia e busca resolver seus conflitos por intermédio da realidade empírica, da relação harmônica dos sistemas e sob uma visão pragmática do resultado, com o fim de assegurar segurança à posterioridade.

Pelo exposto, uma decisão não deve apenas basear-se na norma que estabelece supremacia do interesse público sobre o privado, o chamado dever-ser, em verdade, no momento de decidir sobre aplicação das cláusulas exorbitantes a Administração deve ater-se ao resultado que aquela ação provocará, observando os efeitos que causará no âmbito econômico, político e social.

Adiante, apresentamos dois exemplos: o primeiro, uma decisão não que não observou os aspectos interdisciplinares e não foi pragmática e o segundo uma decisão que, embora seja eivada de supremacia do interesse público sobre o privado, seu resultado foi pragmático.

\footnotetext{
${ }^{190}$ Diante disso, o que seria o novo estilo do direito administrativo? A essa altura do artigo, é possível afirmá-lo: é uma abordagem interdisciplinar que busca em dados tirados da experiência uma hipótese que sirva a reconstruir uma prática ou uma norma jurídica numa ambiência de inovação substantiva. (MENDONÇA, 2014a, p. 196)
} 


\subsection{ASPECTOS INTERDISCIPLINARES: O CASO DA TARIFA ZERO DO MUNICÍPIO DE MARICÁ}

Exemplo de decisão dissociada da relação interdisciplinar se verifica no recente julgamento do Tribunal de Justiça do Estado do Rio de Janeiro ${ }^{191}$ em que foi autorizado o Município de Maricá exercer as atividades de transporte rodoviário de passageiros com tarifa zero. Não obstante a alegação de desequilíbrio econômico-financeiro em decorrência da competição desleal e cláusula de exclusividade de exploração da atividade.

Alguns pontos da decisão merecem destaque: (i) em sede de cognição sumária não houve como comprovar a "superposição de linhas", quer dizer não restou provada a concorrência desleal, posto que os itinerários das linhas não eram conflitantes, (ii) a supressão da linha gratuita afetaria apenas os munícipes, (iii) a mantença da má prestação de serviços do contratado; (iv) eventual, prejuízo financeiro do particular poderá ser aferido ao final da demanda judicial.

Não levamos em consideração as questões processuais que nortearam a decisão prolatada, aqui nos coube observar que a autarquia municipal transporta aproximadamente 3.000 passageiros por mês, logo, levando-se em conta a tarifa modal de $\mathrm{R} \$ 3,15$, o custo anual para transporte dos munícipes giraria em torno de $\mathrm{R} \$ 3.402 .000,00$. Surpreendentemente, o orçamento estimado para o exercício de 2016 foi fixado em $\mathrm{R} \$ 21.000 .000,00192$. Dessa forma, indaga-se, o que deve prevalecer o atendimento do interesse público primário de transporte de passageiros ou resguardar o erário, mediante o enorme déficit apresentado?

A decisão ora trazida ao debate, apenas observou a necessidade de atender o interesse público primário, sem levar em consideração aspectos interdisciplinares e pragmáticos, pois são estarrecedores os prejuízos econômicos e o descumprimento as normas do Direito Financeiro.

Outro ponto dissociado do paradigma atual, é o fato que eventual prejuízo financeiro do particular poderá ser aferido ao final da demanda judicial, tal decisão traz prejuízo imediato a

\footnotetext{
${ }^{191}$ Agravo de Instrumento n ${ }^{\circ} \mathbf{0 0 3 6 8 3 0 - 3 8 . 2 0 1 5 . 8 . 1 9 . 0 0 0 0}$ - VIGÉSIMA CAMARA CIVEL - Relator: DES. MARILIA DE CASTRO NEVES VIEIRA

${ }^{192}$ Entre as principais despesas previstas para o próximo ano, os maiores volumes ficam com as secretarias adjuntas de Obras ( $\mathrm{R}$ \$ 286.847.275,88), Educação ( $\mathrm{R}$ \$ 143.608.914,95) e Saúde ( $\mathrm{R}$ \$ 122.734.246,90), enquanto a Empresa Pública de Transportes (EPT) terá R\$ 21 milhões para seus investimentos. Os gastos com folha de pagamento e encargos sociais serão de $\mathrm{R} \$ 268.457 .818,15$ (já incluído o impacto do novo plano de cargos e salários dos servidores), o que representa $31,71 \%$ do orçamento. O número está bem abaixo do limite determinado pela Lei de Responsabilidade Fiscal, que é de 54\%. Disponível em < http://www.marica.rj.gov.br/?s=noticia\&n=5822>. 16/05/2016.
} 
livre iniciativa privada e a segurança jurídica, visto que o particular terá que arcar com prejuízos financeiros por um período inestimável.

Por fim, a Administração passou a desenvolver as atividades que outrora fora delegada, ao invés de fiscalizar a execução dos serviços. Isto é um retrocesso! O Estado deixa de ser um mediador e intervém de forma direta no domínio econômico, ao passo de exterminar a concorrência193 dos serviços públicos. Ora, concorrência traduz a evolução da eficiência na prestação de serviços públicos à sociedade.

Portanto, o intérprete ao decidir de forma isolada, sem levar em consideração as relações interdisciplinares, sobretudo, os aspectos econômicos, políticos e sociais, sempre correrá o risco de não alcançar o bem comum.

A decisão, que serve como exemplo, como vimos não avaliou os critérios interdisciplinares, e pior, ao decidir o magistrado, ao que parece, não exerceu qualquer introspecção dos conhecimentos dos fatos externos.

\subsection{O PRAGMATISMO COMO INSTRUMENTO DE ARGUMENTAÇÃO NA APLICAÇÃO DAS CLÁUSULAS EXORBITANTES}

De forma distinta ao exemplo anterior, o mesmo Tribunal de Justiça já decidiu no sentido de privilegiar o interesse público sobre o privado, entretanto, aplicando a teoria do pragmatismo, mesmo que de forma intrínseca, ao detectar consequências certas e imediatas que causariam prejuízos ao interesse público, no caso, ao erário194. A lide se estabelece em razão da Administração Municipal rescindir, de forma unilateral, contrato administrativo que continha o objeto de incrementar a recuperação de ativos do Município, com atendimento ao contribuinte, disponibilização de estrutura física, sofware de gestão, call-center e ações de marketing. A motivação da ruptura contratual foi que a contratação "revelou-se onerosa demais, acabando por gerar prejuízo aos cofres públicos municipais, revertendo a expectativa de

\footnotetext{
${ }^{193}$ Nestes exemplos, atividades consideradas serviços públicos, são prestadas por competidores sujeitos em níveis de regulação distintos. Trata-se de um novo traço da regulação dos serviços públicos cuja idéia nuclear é a de incentivar a concorrência nestas atividades, já que são, ainda hoje, muito concentradas. A idéia é oferecer ao operador entrante um regime de prestação mais brando que aquele dispensado ao prestador dominante, com vistas a acirrar a disputa pelo mercado, o que, é certo, traz inúmeras conseqüências benéficas ao usuários de tais serviços. Sobre esta questão, são valiosos os ensinamentos de Santiago Mufioz Machado: "Otra manifestación distinta de las analizadas hasta ahora de las regIas que la Comisión está imponiendo para conseguir la formación de mercados libres en los sectores recientemente desmonopolizados y privatizados, son las medidas conducentes a procurar que los nuevos operadores actúen en condiciones de la máxima igualdad posible con las antiguas empresas monopolistas". (MARQUES NETO, 2002, p.23)

${ }^{194}$ Decisão monocrática. Mandado de Segurança no 0048608-39.2014.8.19.0000 - SÉTIMA CÂMARA CÍVEL Relator: DES. LUCIANO RINALDI
} 
aumento da arrecadação que pudesse superar os custos de cobrança dos débitos, de sorte que, diante do desequilíbrio financeiro surgido, optou a Administração pela rescisão unilateral do contrato, com base na Lei n'8.666/93”.

Vejamos que neste caso, o desiquilíbrio econômico ocorreu de forma reversa, pois foi a Administração que identificou onerosidade excessiva na prestação dos serviços. É evidente que prevaleceu a supremacia do interesse público sobre o privado, na medida que as consequências advindas da relação contratual afetariam o interesse da coletividade. Eis uma decisão pragmática195 que observou a normatividade, as consequências imediatas e futuras e as relações interdisciplinares.

Cabe ressaltar, que a decisão interrompeu, imediatamente, o prejuízo ao erário e ainda assim protegeu os direitos do contratado ao garantir o direito de requerer indenização por eventuais e danos e custos de desmobilização.

O novo paradigma propõe que as decisões que envolvam a execução de contratos administrativos, sejam consubstanciadas na compreensão que nenhum conceito é imutável ou absoluto, por essa razão se indica a aplicação da teoria do pragmatismo como instrumento de flexibilização da realidade, ao levar em conta o momento e as circunstâncias que levam a Administração exercer os privilégios que lhe são conferidos.

Portanto, segundo o filosofo Jonh Dewey o pragmatismo "rejeita todos os tipos de dogmas, valores supremos, autoridades últimas, dualismos, e deseja substituí-los pela incerteza e imprevisibilidade da experiência humana” (POGREBINSCHI, 1977, p. 37).

É evidente que não defendemos uma doutrina que não leva em consideração as normas contidas no sistema jurídico, baseando-se apenas na prática, na consequência e no utilitarismo. Não é isso!

Apenas se pretende indicar a utilização de um método prático, abandonando as teorias dogmáticas e absolutistas e priorizar a análise das consequências da decisão ou do ato. Enfim, podemos dizer que a inserção da teoria do pragmatismo possui a utilidade de incentivar que o exercício dos privilégios da Administração na contratação governamental não seja amparado pelo discurso que "apenas apliquei a lei aos fatos" (MENDONÇA, 2014b, p. 47).

\footnotetext{
${ }^{195}$ Em dois momentos o julgador deixou evidente a aplicação da teoria do pragmatismo, quais sejam: "É que há o risco de que se torne prejudicado o interesse público imediato, caso os prejuízos apontados continuassem a existir com a manutenção prolongada do contrato."; e, "o prolongamento do processo administrativo para que se permitisse a produção de defesa só iria causar mais prejuízos ao erário. E não teria qualquer utilidade prática para a contratada, pois esta não poderia alterar o desiderato administrativo, fundado em razões subjetivas de conveniência e oportunidade".
} 
Segundo a teoria de Richard Posner, o pragmatismo jurídico196, consiste na renúncia de valores imateriais, primando pela consequência e pela razoabilidade sem se afastar da expectativa dos resultados almejados pelo Direito legislado.

Seguindo a metodologia de José Vicente Santos de Mendonça ao tratar da incidência do pragmatismo jurídico no Direito Constitucional Econômico, demonstramos, de forma semelhante, como aplicar esse princípio nos atos ou decisões que tratam sobre as cláusulas de privilégio conferidas à Administração nas contratações governamentais:

Incidir como instrumento argumentativo finalístico na aplicação das normas de prevalência da Administração Pública sobre o contratado. Até porque na maioria das vezes quando o interprete aplica a lei, a consequência será a obtenção da expectativa do legislador, nessa hipótese a decisão não deixou de ser pragmática.

Destarte, inquestionável que o Administrador, de forma prioritária, fundamentará sua decisão com enfoque na norma vigente, utilizando o pragmatismo jurídico como apoio de obtenção de harmonização na relação entre o interesse público e privado, com a finalidade de alcançar o bem comum.

Os resultados, de forma imperiosa, visam a finalidade primordial do Estado, em estrita observância as normas constitucionais197. Esse campo de incidência é relevante ao priorizar a garantia dos objetivos constitucionais, dando azo a proteção dos direitos fundamentais, sobretudo, não permitir violação à livre iniciativa e a concorrência.

A tomada de decisão no exercício dos privilégios da Administração importa em observar as consequências certas e prováveis que deverão resultar no atendimento ao interesse geral. Portanto, o estudo de probabilidade do resultado da decisão não pode deixar de ser feito. No exemplo aqui exposto, fica límpido, que o julgador fundamentou a decisão numa cláusula exorbitante prevista na legislação, contudo, por último analisou as consequências imediatas que acarretariam a perpetuação de prejuízos ao interesse público secundário, noutros termos, a demora na rescisão do contrato resultaria prejuízo contínuo ao erário municipal.

Observe-se, que os dois exemplos são antagônicos, na medida que na decisão judicial favorável ao Município de Maricá as consequências prováveis ao erário serão desastrosas, enquanto que no último exemplo a decisão que deferiu a rescisão unilateral, com o uso da

\footnotetext{
196 Segundo Mendonça (2014b, p. 50) “o pragmatismo filosófico não é inútil ao debate acerca do pragmatismo jurídico. É perfeitamente possível aplicar a matriz pragmatista - consequencialismo, antifundacionalismo, contextualismo - para examinar institutos jurídicos e decisões judiciais, e aproximá-los ou afastá-los dos resultados da incidência de uma teoria do pragmatismo jurídico”.

${ }^{197}$ Nesse ponto, seguindo os ensinamentos de Mendonça (2014b, p. 117), entendemos ser incompatível a teoria de Richard Posner, posto que nosso ordenamento jurídico não admite argumentos opostos à Lei.
} 
supremacia do interesse público sobre o privado, impediu, de forma imediata, os prejuízos ao erário municipal. Portanto, por tais razões que sugerimos que o interprete ao aplicar a teoria do pragmatismo deverá analisar as consequências certas e prováveis, independente de beneficiar um ou outro da relação contratual, o fim almejado sempre deve ser o bem comum.

Assim sendo, para minimizar erros, cabe ressaltar a distinção entre certeza e plausibilidade, como ensina Mendonça (2014b, p. 118): "O juízo de certeza é o mais simples. Entre plausibilidade e probabilidade há diferença de grau. A consequência plausível é, tão somente, uma conjectura razoável; a consequência provável é aquela para a qual concorrem os dados estatísticos, as regras da experiência etc."

Enfim, ao pretender impor o exercício das cláusulas exorbitantes nas contratações governamentais a Administração deverá levar em conta as consequências da sua decisão, afastando-se das manifestas vontades de ações de governo.

(iv) Impõe-se, além das consequências, observar o núcleo comum entre os pragmatistas originais, que consideram o antifundacionalismo e o contextualismo aspectos relevantes para aplicação da teoria do pragmatismo. Sendo necessário desconsiderar aspectos fundacionais, pois cabe ao interprete não se basear em crenças, dogmas e preceitos pretéritos. Do mesmo modo, deve priorizar que as consequências se relacionem ao contexto do caso concreto, para que seus resultados não afetem outras disciplinas ou sistemas.

Portanto, o pragmatismo, seja filosófico ou jurídico, traz à colação três pontos que foram refletidos: i) quando leva em consideração as circunstâncias e o momento em que uma concepção ou decisão foi elaborada; ii) quando adota a mutação e a flexibilidade na interpretação das normas e; iii) quando busca o melhor resultado futuro, sem proporcionar instabilidade nas relações jurídicas ou não jurídicas.

Logo, o pragmatismo não vem proporcionar instabilidade ou insegurança, haja vista, não propor a eliminação das normas e conceitos, apenas transformando-os de acordo com a prática e a experiência adquirida, aperfeiçoando-as com vistas nas consequências da decisão é proferida.

Por derradeiro, deverá a decisão pragmática ser carreada da análise finalística das consequências prováveis e futuras, com o fim de alcançar o interesse geral, não importando se haverá ou não preponderância do interesse público sobre o privado.

\section{CONSIDERAÇÕES FINAIS}


O presente trabalho apresentou adequação de um novo paradigma do Direito Administrativo na hipótese de conflito de interesses na aplicação das cláusulas exorbitantes nos contratos administrativos propriamente ditos. O novo método sugere a observação dos aspectos interdisciplinares, empíricos e pragmáticos.

Evidenciou-se que a abordagem da aplicação se dá pela compreensão de um Estado que deverá apenas intervir na economia para garantir acesso a direitos sociais e por intermédio das teorias do pragmatismo filosófico e jurídico, com o desiderato de alcançar o interesse geral, não importando se houve ou não a prevalência de uma parte sobre a outra.

O novo paradigma importa em acrescentar uma nova perspectiva de interpretação no exercício das cláusulas exorbitantes, não impondo, de forma absoluta, a supremacia defendida pela doutrina tradicional, bem como, não defende a desconstrução do princípio do interesse público sobre o privado, em verdade, se mantem as convergentes ideologias de proteção ao bem comum e proteção aos direitos dos particulares, seja no sentido de reequilibrar a relação contratual ou até mesmo indenizá-los por possíveis perdas e danos.

O julgamento sobre a égide da teoria do pragmatismo, vai além de julgar o caso concreto sob o prisma isolado dos direitos das partes, acrescenta-se novos elementos para assegurar a harmonização das relações interdisciplinares e estudam as consequências prováveis e futuras da tomada de decisão.

Os dois exemplos de julgamentos demonstram que é possível assegurar melhor resultado da decisão na aplicação no novo paradigma. No primeiro caso, não há dúvida que o resultado seria mais satisfatório se o julgador tivesse se atentado para as relações interdisciplinares e para as consequências certas e imediatas, na medida que mesmo atendendo um interesse público primário, o secundário será gravemente afetado, além de gerar insegurança jurídica nas relações contratuais com a Administração, como também, a violação à livre iniciativa e a concorrência. Enquanto no segundo exemplo, fica límpido, que mesmo nos casos que se aplica a supremacia do interesse público sobre o privado é possível obter uma decisão pragmática que resulta em assegurar o bem comum.

Afirmamos, portanto, que as concepções pragmáticas buscam resultados que não venham gerar consequências prejudiciais para a grupo social. Para isso, os pragmáticos afastamse de dogmas ou preceitos pretéritos (antifundacionalismo), logo as modificações das concepções possuem o desiderato de aperfeiçoá-las, visto que o resultado obtido pelo pragmatismo é temporal, pois em momento posterior essa decisão pragmática poderá não ser salutar. Daí a característica temporal da teoria pragmática. 
Não há dúvidas que no sistema jurídico brasileiro a aplicação da teoria do pragmatismo é moderada, embora muitas das vezes essa análise seja realizada de forma implícita, todavia, a proposta não se pretende abandonar a normatividade. Em verdade se propõe que o interprete ao exercer sua discricionariedade observe em última análise as consequências de sua decisão. (MENDONÇA, 2014b, p. 122).

Encerrando, o novo paradigma é o instrumento capaz de minimizar as consequências negativas advindas de decisões que não observam os outros sistemas que se relacionam com o Direito, como por exemplo a economia, a política, a sociologia e a filosofia etc. Não obstante a decisão ser proporcional e atender a supremacia da coletividade sobre o privado, impõe verificar se as consequências prováveis e futuras atenderão o interesse geral da coletividade.

\section{REFERÊNCIAS}

ARAGÃo, Alexandre Santos de. Direito dos Serviços Públicos, $3^{\text {a }}$ ed. São Paulo: Forense, 2013.

AVILA, Humberto. Repensando o "Princípio da Supremacia do Interesse Público sobre o Particular, $11^{\mathrm{a}}$ ed. Salvador: Revista Eletrônica sobre a Reforma do Estado, 2007.

BARROSO, Luís Roberto, Prefácio. In "Interesses Públicos versus Interesses Privados: Desconstruindo o Princípio de Supremacia do Interesse Público"- Rio de Janeiro, Lúmen Júris, 2005.

CAMPILOngO, Celso Fernandes. Serviço Público e Regulação Sistêmica. In: Heleno Taveira Tôrres. (Org.). Serviços Públicos e Direito Tributário. $1^{a}$ ed. São Paulo: Quartier Latin, 2005

CRETELLA JUNIOR, José. As cláusulas "de privilégio" nos contratos administrativos. Revista de Direito Administrativo. no 161. p. 7-28, jul./set., 1985.

GABARDO, Emerson; HACHEM, Daniel Wunder. O suposto caráter autoritário da supremacia do interesse público e das origens do direito administrativo: uma crítica da crítica. In: BACELLAR FILHO, Romeu Felipe; HACHEM, Daniel Wunder (Coord.). Direito administrativo e interesse público: estudos em homenagem ao Professor Celso Antônio Bandeira de Mello. Belo Horizonte: Fórum, 2010. p. 155-201 ed. Rio de Janeiro: Lumen Juris, 2010. 
MARÇAL, Justen Filho. Comentários às Lei de Licitações e Contratos Administrativos. 16 ed. São Paulo: Editora Revista dos Tribunais, 2014.

MARQUES NETO, Floriano Peixoto de Azevedo. A nova regulação dos serviços públicos. Revista de Direito Administrativo, Rio de Janeiro, v. 228, p. 13-29, Abr./Jun. 2002.

MARSHALL, Tomaz Humphrey. Cidadania, classe social e status. Rio de Janeiro: Zahar Editores. 1967

MEIRELLES, Hely Lopes. Direito Administrativo Brasileiro, $41^{\text {a }}$ ed. São Paulo: Malheiros, 2015.

MENDONÇA, José Vicente Santos de. A verdadeira mudança de paradigmas do direito administrativo brasileiro: do estilo tradicional ao novo estilo. Revista de Direito Administrativo, Rio de Janeiro, v. 265, p. 179-198, jan./abr. 2014

MENDONÇA, José Vicente Santos de. Direito Constitucional Econômico: A Intervenção do Estado na Economia à Luz da Razão Pública e do Pragmatismo. Rio de Janeiro: Forum. 2014

MOREIRA NETO, Diogo de Figueiredo. Curso de Direito Administrativo, $16^{\mathrm{a}}$ ed. Rio de Janeiro: Forense. 2014

POGREBINSCHI, Thamy. Pragmatismo : teoria social e política. Rio de Janeiro: Relume Dumará, 2005

ROBERTO GRAU, Eros. Parecer sobre CONCESSIONÁRIA DE SERVIÇO PÚBLICO BENS PÚBLICOS - DIREITO DE USO. Revista de Direito Administrativo, Rio de Janeiro, v. 218, p. 343-356, 1999.

SARMENTO, Daniel - "Interesses Públicos vs. Interesses Privados na Perspectiva da Teoria e da Filosofia Constitucional", in "Interesses Públicos versus Interesses Privados: - Desconstruindo o Princípio de Supremacia do Interesse Público"- Rio de Janeiro, Lúmen Júris, 2005. 
THE INFLUENCE INTERDISCIPLINARY RELATIONS AND THEORY

PRAGMATISM THE APLICATTION OF THE CLAUSES OF PRIVILEGES IN

HIRING GOVERNMENT

\begin{abstract}
This article a qualitative approach, developed literature on the divergent doctrinal understandings about the exorbitant clauses conferred the Public Administration. The conflicts in the legal relationship of government procurement should not be resolved through absolutist interpretation of the supremacy of one interest over another or exclusive weighting values of conflicting rights. The proposal for a new paradigm seeks to enhance the interpretation at the time of the act, establishing concepts related to aspects of interdisciplinary, empirical and pragmatic relationship. The proposed method it comes to the final analysis the moment of the decision notice if the decision will affect other systems and also the probable and immediate consequences, with the desideratum to safeguard the common good, without discarding the normativity. Therefore, the judge imposes the duty to observe the likely outcomes, in order to safeguard the fundamental purpose of the state, although the decision is proportionate or not will favor the interests of government.
\end{abstract}

Keywords: Clauses. Exorbitant. Pragmatism. 